LETTERS

If you have a burning desire to respond to a paper published in Sex Transm Inf, why not make use of our "rapid response" option?

Log on to our website (www.sex transinf.com), find the paper that interests you, click on "full text" and send your response by email by clicking on "eletters submit a response".

Providing it isn't libellous or obscene, it will be posted within seven days. You can retrieve it by clicking on "read eletters" on our homepage.

The editors will decide, as before, whether to also publish it in a future paper issue.

\section{HIV epidemicity in context of STI declines: a telling discordance}

Decosas and Padian report, but do not discuss, a noteworthy disassociation in epidemic trajectory between human immunodeficiency virus (HIV) and sexually transmitted infections (STI) in Zimbabwe. ${ }^{1}$ They cite estimates that, between 1990 and 1999, HIV prevalence increased linearly from $9 \%$ to $25 \%$, while STI syndrome reports declined substantially, from 963436 cases to 727788 . The authors not only believe that observed STI declines are real, but cite increases in reported condom use by high risk people (for example, prostitute women truck drivers, miners, and young people) as supporting evidence. What is not clear is why HIV prevalence would increase markedly coevally with increasing condom use in high risk populations and with decreasing STI incidence. Assuming synergism between STI and HIV transmission, ${ }^{2}$ one would expect that a burgeoning and sexually mediated HIV epidemic would be accompanied by corresponding increases in STI transmissions. An estimated increase in HIV prevalence from $9 \%$ to $25 \%$ in a decade, implying a $12 \%$ annual epidemic growth rate, is not likely to be due to differences between HIV, a chronic infection that accumulates in a reservoir, and STI, which tend not to. Does this anomaly require clarification?

Recent analyses ${ }^{34}$ suggest that a large proportion of HIV infections, especially in sub-Saharan Africa, ${ }^{5}$ may be a consequence of unsafe medical injections. This undersuspected and scientifically underexplored transmission vector is overlooked by the authors as well (exception: "blood safety" in fig 1). Theirs is not the first report of an epidemiologically suspicious anomaly between STI and HIV trends in Africa ${ }^{6}$ and, if others' suspicions are correct, ${ }^{3-5}$ it is unlikely to be the last.

J J Potterat

Independent consultant, Colorado Springs, $\mathrm{CO}$ USA

\section{Institute of Medical Psychology, University} Tübingen, Germany

\section{Correspondence to: Stuart Brody;} stuartbrody@hotmail.com

\section{References}

1 Decosas J, Padian N. The profile and context of the epidemics of sexually transmitted infections including HIV in Zimbabwe. Sex Transm Infect 2002;78(Suppl I): i40-6.

2 Wasserheit JN. Epidemiological synergy: interrelationships between human immunodeficiency virus infections and other sexually transmitted diseases. Sex Transm Dis 1992:19:61-77.

3 Holding R, Carlsen W. Deadly needles: epidemic's devastating toll. San Francisco Chronicle.29 October 1998:Alff. Internet version accessed 19 August 2002 http://sfgate.com/cgi-bin/article.cgi?file=/ chronicle/archive/1998/10/29/ MNIONED. DTL\&type $=$ specia

4 Gisselquist D, Rothenberg R, Potterat J, et al. HIV infections in sub-Saharan Africa no explained by sexual or vertical transmission. Int J STD AIDS (in press).

5 Drucker E, Alcabes PG, Marx PA. The injection century: massive unsterile injections and the emergence of human pathogens. Lancet 2001;358: 1989-92.

6 Lagarde L, Auvert B, Carael M, et al. Concurrent sexual partnerships and HIV prevalence in five urban communities of sub-Saharan Africa. AIDS 2001;15:877-84.

Accepted for publication 28 August 2002

\section{Vaginal infection by Enterobacter sakazakii}

In August 2001, a 26 year old woman seen a our outpatient clinic in Budapest complained of vulvar pruritus and vaginal discharge in the preceding 2 weeks. The only risk factor she admitted was that she had bathed in the resort lake Balaton a few times a week before the onset of symptoms, when the water was unusually warm $\left(26-28^{\circ} \mathrm{C}\right)$. Examination revealed vulvovaginitis with mucous discharge at $\mathrm{pH}$ 5.5. A vaginal smear showed a large number of polymorphonuclear leucocytes, Gram negative rods, but no Lactobacillus. Culture on blood agar at $37^{\circ} \mathrm{C}$ for 48 hours resulted in yellow pigmented, bright, tough colonies. Biochemical analysis ${ }^{1}$ verified Enterobacter sakazakii. Standard disc diffusion technique, ${ }^{2}$ on Mueller-Hinton agar (Becton Dickinson, Sparks, MD, USA) using commercial discs (Oxoid, Basingstoke, UK), revealed sensitivity to carbenicillin, netilmycin, cefazolin, ofloxacin, tetracycline, and gentamicin; limited sensitivity to erythromycin; and resistance to ampicillin, clindamycin, nalidix acid, furadantin. This pattern is common in recent isolates. ${ }^{3}$ Empirical treatmentstarting before laboratory data were available — with intravaginal Pimafucort ointment ( $1 \%$ natamycin, $0.25 \%$ neomycin, $0.5 \%$ hydrocortisone) for 7 days resulted in a complete recovery in 2 weeks, at which time the vagina was colonised by Streptococcus agalactiae. The following week a normal Lactobacillus flora at $\mathrm{pH} 4.2$ returned.

Nearly 50 E sakazakii infections resulting in meningitis, necrotising enterocolitis, and one urine infection of newborns have been documented. E sakazakii have been recovered from their blood, spinal fluid, throat, trachea, stomach aspirates, and rectum. Newborns were premature, and fed on powdered milk formula, which is the known source of infection. ${ }^{3}$ The means of its contamination is not known. For affected newborns, vaginal delivery does not seem to be a risk factor, since no colonisation of the mother's genital tract has been reported. Less than 20 isolates have been obtained from children and adults, including eight from urine and one from genital secretion. Patients had either neoplasm or other serious underlying conditions, but their clinical details were not available. In both newborns and adults occasional coinfections with Serratia marcescens, Staphylococcus aureus, Enterococcus faecalis, or Candida albicans were reported. ${ }^{3}$

The normal habitat, reservoir, and pathogenesis of $E$ sakazakii are unknown. No cultivation from environmental sources (surface water, animals, raw cow's milk, etc) has been successful, ${ }^{3}$ except recently from the gut of fruit flies. ${ }^{6}$ The rare related species $E$ intermedium causing urinary tract infection, was found in drinking water and soil. ${ }^{5}$ Our case strongly suggested that warm surface water was the source of infection. The unusually high thermal resistance of $E$ sakazakii ${ }^{3}$ might contribute to its survival during the manufacture powdered milk batches. ${ }^{4}$ It is important to remember that the stomach of newborns, especially that of premature babies, lacks free acid and is less acidic than that of adults. Ingested milk preparations remaining neutral or slightly alkaline in their stomach ensure survival and subsequent infection in the alkaline intestine. This pathomechanism is similar to $\mathrm{pH}$ increase in vaginal infections in the lack of Lactobacillus flora. The detrimental effect of $E$ sakazakii infection is also reflected by the fact that recolonisation by the normal flora and a $\mathrm{pH}$ shift towards physiological level could be achieved only gradually in our patient.

J Ongrádi

National Institute of Dermato-Venereology, Budapest VIII, Mária utca 41, Hungary 1085; ongios@hotmail.com

\section{References}

1 Murray PP, Baron EJ, Pfaller MA, et al, eds. Manual of clinical microbiology. 7th ed. Washington DC: ASM Press, 1999.

2 The National Committee for Clinical Laboratory Standards. Performance standards for antimicrobial susceptibility testing: eight informational supplements. Vol 18, No 1. Wayne, PA: The Committee, 18, No 1.

3 Lai KK. Enterobacter sakazakii infections among neonates, infants, children, and adults: case reports and a review of the literature. Medicine (Baltimore) 2001;80:113-22.

4 Van Acker J, de Smet F, Muyldermans G, et al. Outbreak of necrotizing enterocolitis associated with Enterobacter sakazakii in powdered milk formula. J Clin Microbiol 2001;39:293-7.

5 Varaldo PE, Biavasco F, Mannelli S, et al. Distribution and antibiotic susceptibility of extraintestinal clinical isolates of Klebsiella, Enterobacter and Serratia species. Eur J Clin Microbiol Infect Dis 1988;7:495-6.

6 Kuzina LV, Peloquin JJ, Vacek DC, et al. Isolation and identification of bacteria associated with adult laboratory Mexican fruit flies, Anastrepha ludens (Diptera: Tephritidae). Curr Microbiol 2001;42:290-4. 


\section{Successful use of valciclovir in a case of recurrent urticaria associated with genital herpes}

Urticaria is a common skin condition but the symptoms and signs can be extremely distressing. The condition is often idiopathic. The management of urticaria can be frustrating even when triggers are identified. ${ }^{2}$ We describe a case of recurrent urticaria associated with genital herpes attacks and a successful use of suppressive therapy with valaciclovir.

A 35 year old white woman presented in March 2000 to a genitourinary medicine (GUM) clinic with 5 year history of recurrent lesions typical of genital herpes simplex virus (HSV) infection occurring almost every month. She had also been developing physical urticaria manifesting as itchy weals on pressure areas of the body, approximately 24 hours before the onset of genital HSV attacks. The lesions showed no characteristics of erythema multiforme or vasculitis. Each urticarial at tack lasted from 20-30 minutes and had a cholinergic element being exacerbated by exercise and heat. Antihistamines were not effective. She had contact sensitivity to perfumes, make up, and coloured bath products. There was no history of angioedema, other atopic disease, or drug allergies. She was otherwise well and on no medication.

Culture for HSV was negative. However serology was positive for HSV type I IgG antibody. HSV type 2, hepatitis B and C serology were negative. Her IgE level was normal. Immunological investigations including CD4/ CD8 count showed no evidence of immunodeficiency.

Her HSV attacks were frequent and distressing. She began suppressive therapy with valciclovir $500 \mathrm{mg}$ twice a day and antihistamines in March 2000 and the symptoms were well controlled. Both urticaria and herpes recurred when the valciclovir therapy was discontinued after 6 months. She recommenced her therapy in October 2000 but required higher doses of valciclovir to control her symptoms. She is currently taking valaciclovir $1 \mathrm{~g}$ twice daily and cetirizine $10 \mathrm{mg}$ daily. She had a single episode of urticaria associated with genital herpes precipitated by intense sunlight exposure in September 2001 and had no further attacks since then.

Urticaria can be triggered by a large number of diverse allergens including sexually transmitted infections such as hepatitis $B$ virus. ${ }^{3}$ A case of chronic urticaria preceding genital herpes and a successful treatmen with a short course of aciclovir has been described. However, the long term follow up of this patient was not known. ${ }^{4} \mathrm{~A}$ recent study in Ohio has reported a successful use of maintenance therapy with aciclovir in five out of 12 patients with chronic urticaria; none had genital herpes. ${ }^{5}$ In our patient, control of both genital herpes and recurrent urticaria with valciclovir therapy suggests a close temporal association between the onset of urticaria and development of herpetic lesions. The exact role of HSV in the pathogenesis of urticaria is unknown but it may be related to hypersensitivity reaction to viral antigens. Antiviral agents may be effective by suppressing these antigens

This case demonstrates the importance of early recognition of urticaria associated with HSV infections in order to avoid delay in instituting antiviral treatment in GUM clinics or other settings for this disabling skin condition.

A Khunda, M Kawsar, J M Parkin, G E Forster

Infection and Immunity Clinical Group, Barts and The London NHS Trust, London E1 1BB, UK

Correspondence: Dr A Khunda, Ambrose King Centre, Royal London Hospital, Whitechapel, London E1 1BB, UK; khunda@btinternet.com

\section{References}

1 Kaplan AP. Chronic urticaria and angioedema. N Engl J Med 2002;346:175-9.

2 Sharma JK, Miller R. Chronic urticaria: review of the literature. J Cutaneous Medicine and Surgery 1999;3:221-8.

3 Sarkany I. Cutaneous manifestations of hepatobiliary disease. In: Fitzpatrick TB, Eizen AZ, Wolf $\mathrm{K}$, et al. Dermatology in general medicine. 3rd ed. New York: McGraw Hill, 1987;2:947-64.

4 EL Sayed F, Marguery MC, Periole H, et al. Urticarial manifestations associated with herpes simplex virus type 2. Genitourin Med 1995;71:96.

5 Shelley WB, Shelley ED. Acyclovir therapy for angioedema and chronic urticaria. Cutis $1997 \cdot 59: 85-8$

Accepted for publication 14 June 2002

\section{Inhibition of Neisseria gonorrhoeae by vaginal lubricants}

Microbiology culture remains the diagnostic standard for gonococcal infection. Isolation of the pathogen confirms the clinical diagnosis and allows assessment of the antimicrobial susceptibility of the gonococcal strain, guiding effective therapy. The sensitivity of endocervical swab culture has been reported as $80-90 \%$ but this varies with the quality of culture media and adequacy of the specimen. The gonococcus is a nutritionally demanding bacterium, readily inhibited by adverse culture conditions.

For decades, doctors in genitourinary medicine have been advised to lubricate metal vaginal specula with water only. With the increasing use of disposable vaginal specula, which are more difficult to insert, some workers have promoted the use of vaginal lubricants, such as KY jelly, to reduce patient discomfort during clinical examination and specimen collection.

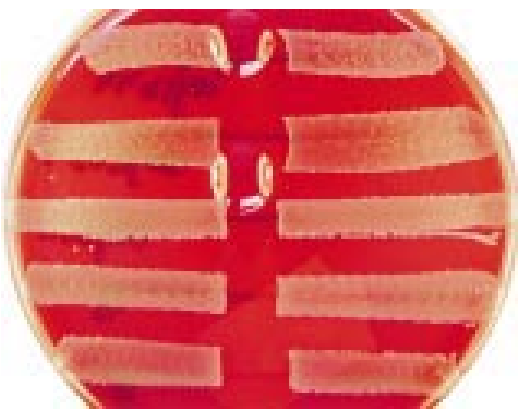

Figure 1 Five randomly selected clinical strains of Neisseria gonorrhoeae growing on gonococcal sensitivity agar. Note the central region of the plate where a line of $K Y$ jelly has inhibited growth.

Figure 1 shows five randomly selected clinical strains of Neisseria gonorrhoeae inoculated by swab $\left(10^{4} / \mathrm{ml}\right)$ and growing readily on gonococcal sensitivity agar except in the central region of the plate where a line of KY jelly has inhibited growth.

Some studies have demonstrated the inhibitory actions of various vaginal lubricants, including $\mathrm{KY}$ jelly, against $N$ gonorrhoeae, while others have found KY jelly to be relatively non-toxic to both chlamydia and gonococci. $^{3}$

In view of these conflicting findings, prospective studies are required to assess the clinical significance of using vaginal lubricants when collecting specimens for gonococcal culture. Pending the completion of such studies we recommend that vaginal lubricants should not be used when obtaining endocervical samples for microbiological investigation.

\section{Contributors}

REH, design of practical work, literature review, production of first draft of manuscript; JDJ, performance of practical work, literature review, critical comment on draft manuscript; FD identification of clinical issue, literature review, critical comment on draft manuscript.

R E Holliman, J D Johnson, F Davidson

St George's Hospital, Blackshaw Road, London SW17 OQT, UK

Correspondence to: Dr Holliman rhollima@sghms.ac.uk

\section{References}

1 Sparling PF, Hansfield $\mathrm{HH}$. Neisseria gonorrhoeae. In: Mandell GL, Bennett JE, Dolin R, eds. Principles and practices of infectious diseases. 5th ed. Philadelphia: Churchill Livingstone, 2000:2242-58.

2 Singh B, Cutler JC. The effect of vaginal ubricants on Neisseria gonorrhoeae. Am J Obstet Gynecol 1976:126:365-9.

3 Osborn MF, Johnson AP. Effect of various analgesics and lubricants on isolation of Chlamydia trachomatis and Neisseria gonorrhoeae. J Clin Microbiol $1982 ; 15: 522-4$

Accepted for publication 20 June 2002 